Article

\title{
Toxic Gas Emissions from Damaged Lithium Ion Batteries-Analysis and Safety Enhancement Solution
}

\author{
Antonio Nedjalkov ${ }^{1, *}$, Jan Meyer ${ }^{1}$, Michael Köhring ${ }^{2}$, Alexander Doering ${ }^{2}$, \\ Martin Angelmahr ${ }^{2}$, Sebastian Dahle ${ }^{3}$, Andreas Sander ${ }^{4}$, Axel Fischer ${ }^{5}$ and \\ Wolfgang Schade ${ }^{1,2}$
}

1 Institute of Energy Research and Physical Technologies, Clausthal University of Technology, Am Stollen 19H, 38640 Goslar, Germany; jan.meyer@tu-clausthal.de (J.M.); wolfgang.schade@hhi.fraunhofer.de (W.S.)

2 Department Fiber Optical Sensor Systems, Fraunhofer Heinrich Hertz Institute, Am Stollen 19H, 38640 Goslar, Germany; michael.koehring@hhi.fraunhofer.de (M.K.); alexander.doering@hhi.fraunhofer.de (A.D.); martin.angelmahr@hhi.fraunhofer.de (M.A.)

3 Institute of Energy Research and Physical Technologies, Clausthal University of Technology, Leibnizstrasse 4, 38678 Clausthal-Zellerfeld, Germany; s.dahle@pe.tu-clausthal.de

4 Knein Technische Textilien GmbH, Am Boscheler Berg 32a, 52134 Herzogenrath-Merkstein, Germany; andreas.sander@ktex-gmbh.de

5 CUTEC Institut GmbH, Leibnizstraße 21-23, 38678 Clausthal-Zellerfeld, Germany; axel.fischer@cutec.de

* Correspondence: antonio.nedjalkov@tu-clausthal.de; Tel.: +49-5321-3816-8408; Fax: +49-5321-3816-8401

Academic Editor: Andreas Jossen

Received: 7 December 2015; Accepted: 29 February 2016; Published: 7 March 2016

\begin{abstract}
Lithium ion batteries play an increasing role in everyday life, giving power to handheld devices or being used in stationary storage solutions. Especially for medium or large scale solutions, the latter application confines a huge amount of energy within a small volume; however, increasing the hazard potential far above the common level. Furthermore, as the safety hazards of lithium ion cells have been known for years, impressively shown by several burning cars or laptops, the need for a further enhancement of the safety of these systems is rising. This manuscript presents measurements of the gas emission from lithium ion batteries in case of a malfunction for different scenarios, showing a large variety of species with mostly toxic to highly toxic properties. The measurements were carried out using a combination of gas chromatography-mass spectrometry (GC-MS), quadrupole mass spectrometry (QMS), photoacoustic spectroscopy, and chemical analysis. It is shown that the inflammation of a cell can be overcome, also preventing a cascading effect to neighboring cells, but giving rise to worse toxic gas emission. Furthermore, a filtration concept is presented that decreases the concentration of the emitted components significantly and promises filtration below immediately dangerous to life or health (IDLH) equivalent levels.
\end{abstract}

Keywords: lithium ion; battery safety; thermal runaway; cell venting; health hazard; gas filtration

\section{Introduction}

Energy storage is one of the key topics of scientific and engineering research in order to provide a reliable concept for the power supply in the future. The technical requirements for storage technologies differ strongly depending on the specific application. While a short, and even ultra-short, storage of energy is needed for power grid stabilization, the growing market share of renewable energy sources constantly increases the need for $24 \mathrm{~h}$ energy storage solutions [1]. Conventional battery technologies, like lead-acid batteries, simply do not reach the requirements in terms of power and energy density to overcome this shortage in power storage demand [2,3]. The most promising technology to solve this problem for the next decades is lithium ion technology. With their advanced state of technology and the wide operation in consumer electronics, lithium ion batteries are the perfect candidate for 
e-mobility, clean room, or critical infrastructure power solutions and even large scale stationary energy storage [4-6].

Nevertheless, safety issues become more and more important, because of the increasing energy content in storage devices. In recent years, several accidents have shown the hazard potential of lithium ion cells; primary safety hazards are the ignition of the cell and its toxic emission gases $[7,8]$.

This work presents investigations on the gas emission from off-the-shelf, large-scale lithium ion batteries for different enclosure conditions in case of an internal failure and demonstrates the feasibility of a fire prevention setup, as well as a filtration of the hazardous components.

\section{Experimental}

\subsection{Measurement Setup}

Figure 1 shows the experimental setup used for the emission measurements; three different scenarios have been under test. For each scenario, the lithium ion cell was mounted at the bottom of a plastic barrel (120 L, polyethylene (PE)). Pouch cells consisting of a layered cathode crystal structure from a composite complex of nickel, manganese, and cobalt (NMC) with an electrical capacity of $40 \mathrm{Ah}$ (LiTec Battery GmbH, Kamenz, Germany) were used. The cell's anode material is graphite. From the cell's material safety data sheet it is known that the electrolyte composition is based on ethyl methyl carbonate (EMC) and ethylene carbonate $(\mathrm{EC})$ in unknown weight ratios using lithium hexafluorophosphate $\left(\mathrm{LiPF}_{6}\right)$ as the conducting salt. In order to provoke a reproducible and strong reaction similar to the event of an internal failure, the setup was equipped with a penetration test device (mass: $1.7 \mathrm{~kg}$; height: $0.8 \mathrm{~m}$; nail diameter: $3.8 \mathrm{~mm}$ ), for a test similar to SAND2005-3123 [9]. Each cell under test was slightly overcharged to about $4.3 \mathrm{~V}$ in order to guarantee a thermal runaway after the nail penetration device was triggered. A pumping system with integrated temperature, pressure and flow sensors (DESAGA GS 212) was used to carry the emission gases to the analytics setup. The pumping system consisted of one suction regulator per measuring device, these are one for the activated charcoal tube, one for the silica gel tube and one for the wash-bottle with sodium hydroxide. Therefore, the suction regulators were operated in parallel in order to guarantee similar flow characteristics for each measuring device. The suction regulators' flow rates were set to around $1.5 \mathrm{~L} / \mathrm{min}$. The gas mixture was led by polytetrafluoroethylene (PTFE) tubing to the aforementioned analytics. The tubing for each measuring device was of similar length and chosen as short as possible (1-2 m); moreover it was not externally heated and at ambient temperature. Although this can lead to condensation of gas in the tubes, this effect can be neglected for a relative comparison between the three scenarios.

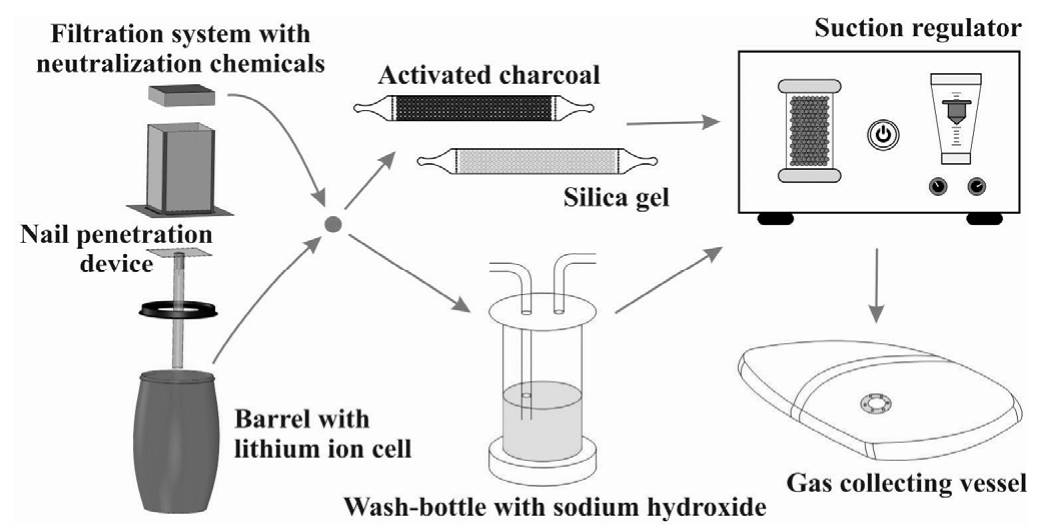

Figure 1. Schematic experimental setup for the determination of harmful battery gas substances. Polytetrafluoroethylene (PTFE) tubing was used to connect all components with a separate suction regulator for each tube.

The experimental scenarios can be described as follows: 
(1) Catching fire: a single bare lithium ion cell is mounted within the barrel. The barrel is shut partly by a cover, which prevents the barrel from explosion but retains most of the emission gases. PTFE tubing leads the gas mixture to the analytics.

(2) Fire prevention: conducted as Experiment 1, the cell under test is, additionally, wrapped within a specially-developed textile composite structure which is gas permeable but prevents flying sparks (FlotreX S500, Knein Technische Textilien GmbH, Herzogenrath-Merkstein, Germany). This cover material is made out of three layers: a fiberglass mesh, a finely-pored pure glass fleece, and a knitted fabric made of stainless steel-reinforced para-aramid fibers. Video "Experimental Setup Scenario 2" in Supplementary Materials presenting this particular experimental setup is available in the online version.

(3) Gas filtration: the experiment, as described under 2 is repeated using a tightly sealed barrel with a gas filtration unit mounted on top. The unit consists of five different stages: a particle filtration grid, three pellet layers of $18 \mathrm{dm}^{3}$ activated charcoal, $9 \mathrm{dm}^{3}$ potassium permanganate and $9 \mathrm{dm}^{3}$ activated alumina, as well as a fine particle filter (CCP 610/210/510, SF 14, Viledon Freudenberg, Weinheim, Germany) (Figure 2). A gas bag is used to collect all gas emission behind the filtration; the PTFE tubing is inserted into this bag.

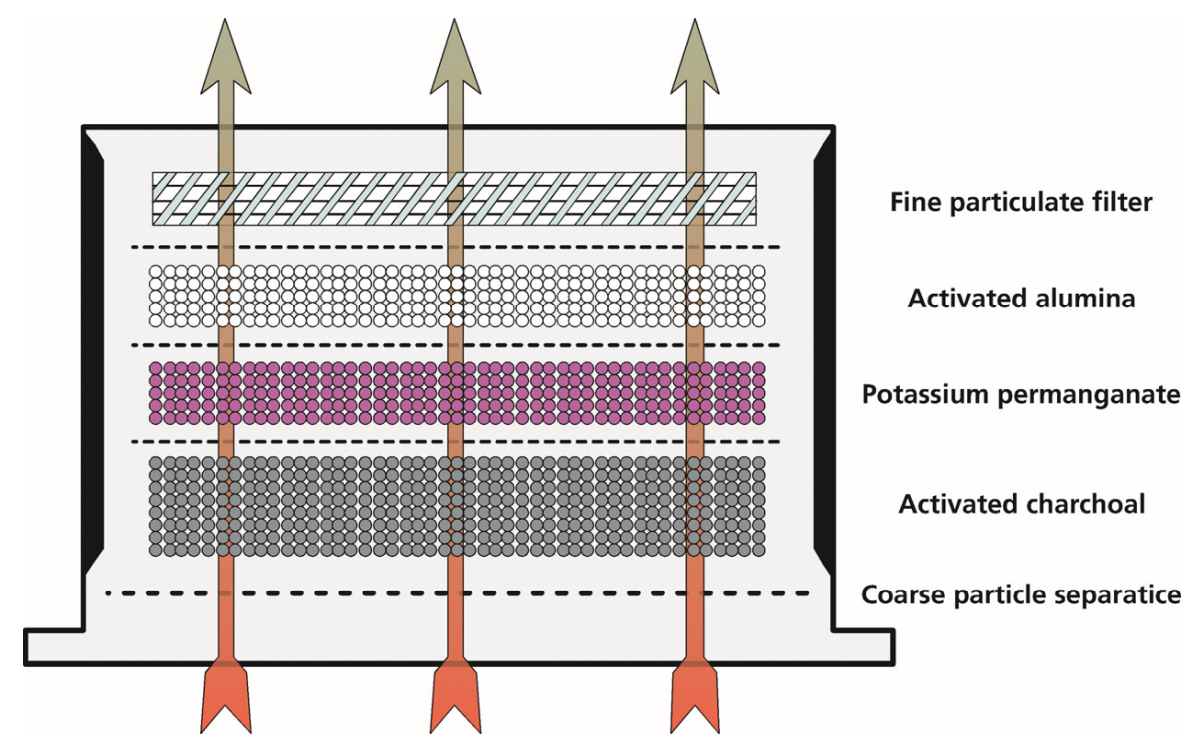

Figure 2. Schematic drawing of the filtration unit setup; five filtration stages are used. The size of the filtration unit is about $30 \times 30 \times 60 \mathrm{~cm}^{3}$.

\subsection{Analytical Methods}

First investigations on the emission gases from lithium ion cells and former works [10-12] showed, that a large variety of species were to be expected. As no state-of-the-art analysis system is known that is capable of a cross-sensitivity free detection of all expected emission components, different spectroscopic and chemical analysis techniques were combined. Gas chromatography-mass spectrometry (GC-MS) was used to detect larger molecules, mainly volatile organic compounds, starting from about four carbon atoms per molecule. Smaller components were determined via quadrupole mass spectrometry (QMS), starting from $1 \mathrm{u}$. In order to get insight in the time dependence of the reaction, an optical sensor based on quartz-enhanced photoacoustic spectroscopy (QEPAS) was used to detect CO, exemplarily. For its radical behavior, HF was determined chemically via ion chromatography (IC) and conductivity measurements. In order to suppress reactions with other species before its detection the HF was dissolved in wash bottles; see Section 2.2.3 for details. It is assumed that all detected fluoride ions result from dissociated HF. 


\subsubsection{Gas Chromatography-Mass Spectrometry}

Gaseous samples for gas chromatographic analyses were collected using test tubes filled with activated charcoal (Aktivkohle Typ G, Dräger, Lübeck, Germany) and silica gel (Silica Typ G, Dräger), respectively. The sorbents were extracted with carbon disulfide for activated charcoal and methanol for silica gel. The screenings for organic compounds were carried out with a Shimadzu Europe GC-MS QP 5050 gas chromatograph (Duisburg, Germany). A Restek Rxi-5 Silms column was used (60 m, inner diameter: $0.25 \mathrm{~mm}$, film $0.25 \mu \mathrm{m}$, Bellefonte, PA, USA).

\subsubsection{Quadrupole Mass Spectrometry}

A commercial gas analyzing system (MFM Analytical Systems, Multigas Analyzer MGA, Clausthal-Zellerfeld, Germany) is employed to determine the composition of the filtered gas. The MGA uses a quadrupole mass spectrometer together with the combination of a turbo molecular pump and a scroll pump. The internal gas inlet system consists of an ultra-high vacuum (UHV) leak valve, thus having no influence on the gas composition in contrast to other common setups, e.g., capillary tubes.

For the quantitative analysis of the mass spectra, background spectra prior to the gas dosage were subtracted from the measured data. Fragmentation intensities for all gas components have been taken from Stein [13] or own measurements. Due to a lack of references for some of the detected compounds, no correction for relative sensitivity factors was carried out.

\subsubsection{HF Determination via Ion Chromatography}

Gaseous samples for the fluoride determination were collected in wash bottles filled with $40 \mathrm{~mL} 0.1 \mathrm{M} \mathrm{NaOH}$, each. Portion of the samples were transferred to a Metrohm 761 Compact IC ion chromatograph (Herisau, Switzerland). An ASUPP 4 column with a mixture of $1.8 \mathrm{mmol}$ $\mathrm{Na}_{2} \mathrm{CO}_{3} / 1.7 \mathrm{mmol} \mathrm{NaHCO}_{3}$ was used as eluent. Detection was performed by conductivity measurement. The detection limit for $\mathrm{HF}$ is $0.7 \mathrm{ppm}$ and the measurement was performed according to VDI guideline 2470 .

\subsubsection{Quartz-Enhanced Photoacoustic Spectroscopy}

In order to gain additional information about the processes and its emissions, an optical sensing scheme was used. QEPAS exploits highly resonant micro tuning forks to detect the photoacoustically-induced sound wave emitted by the target gas mixture [14]. As this technique uses the optical absorption features of the target species for detection instead of measuring their mass, an additional set of information can be acquired to overcome uncertainties of the other detection methods (e.g., molecules with identical mass). Furthermore, QEPAS enables an online measurement, giving information about the temporal behavior of the signal. As one critical component of the presented measurements, $\mathrm{CO}$ was chosen as target gas; optical excitation is achieved using a fiber-coupled distributed feedback (DFB) diode laser near $1570 \mathrm{~nm}$.

\section{Results and Discussion}

For each experiment an emerging gas amount of approximately 200 SL (5 SL/Ah) caused by the induced thermal runaway was observed. Figure 3 shows the retrieved data from GC-MS, QMS, and QEPAS for the measurements of Scenario 2. These graphs were chosen exemplarily, as the gas mixtures from Scenario 2 show far more variety and concentration of hazardous substances-155 in all. It can be seen that most substances appear in the GC-MS spectrum retrieved from the charcoal sample (Figure 3a), whereas far fewer components adsorb on silica (Figure 3b). In the QMS-spectrum, the expected composition of atmospheric air mixed with the species from the battery emission can be seen. Although the in situ measurement with the QEPAS-sensor was performed only for Scenario 2, it shows a good insight of the temporal behavior of the process, starting with the emission peak shortly 
after the nail penetration and nearly exponentially decaying over time. Furthermore, it underlines the high CO content detected by QMS for Scenarios 2 and 3.

More detailed insight into the measurement results can be gained by a comparison of the three scenarios. Based on the quantity, dangerousness, and toxicity of the respective components, a selection of 11 crucial gas mixture constituents was chosen from the measurement data. In Table 1, the respective substances and their hazard potential [15] are listed, a diagram depicting the corresponding concentrations for all three scenarios is shown in Figure 4.
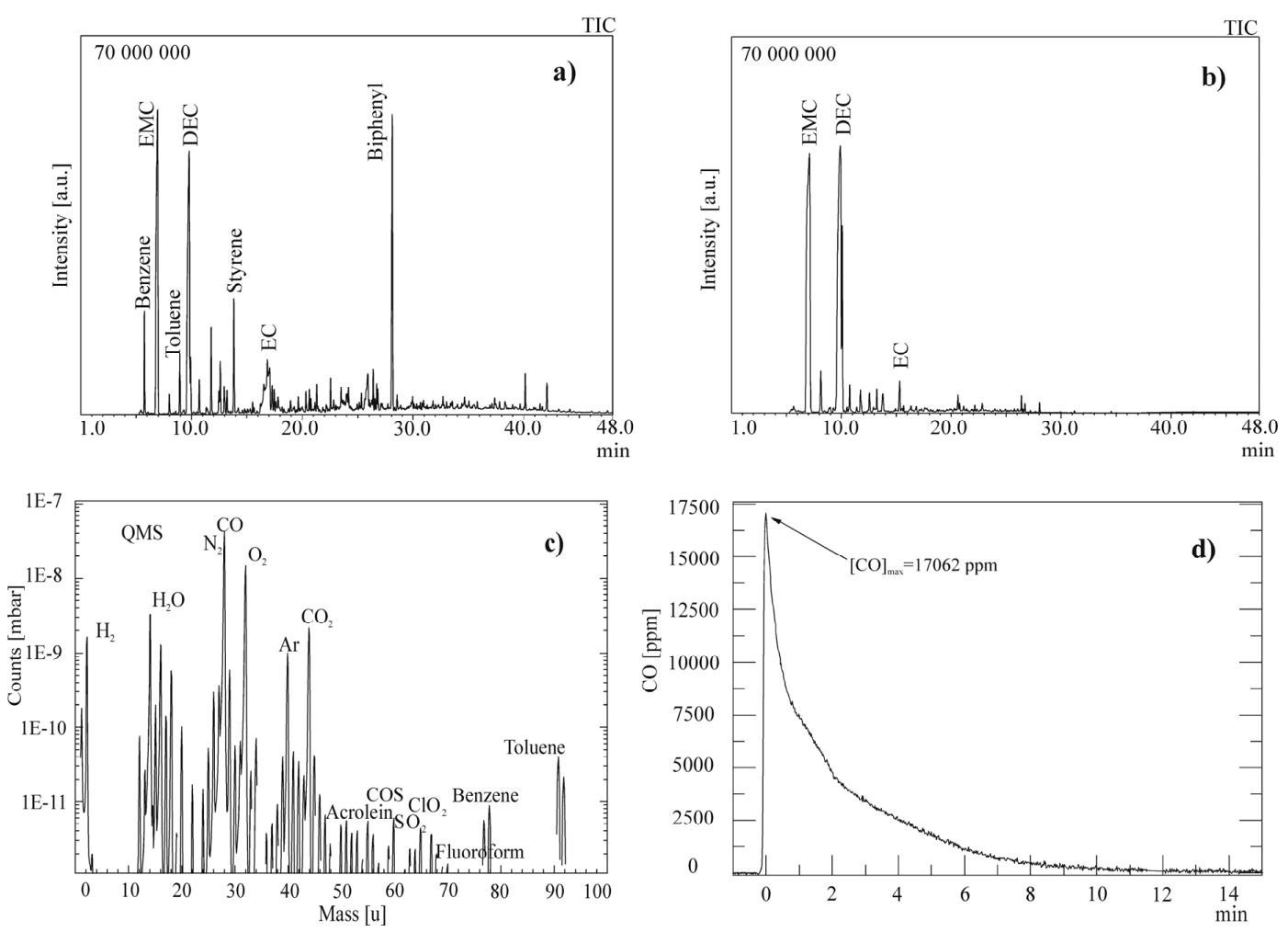

Figure 3. Results of the gas chromatography-mass spectrometry (GC-MS) analysis with (a) activated charcoal tube and (b) silica gel tube of (c) the quadrupole mass spectrometry (QMS) analysis and (d) the quartz-enhanced photoacoustic spectroscopy (QEPAS)-measurement for Scenario 2.

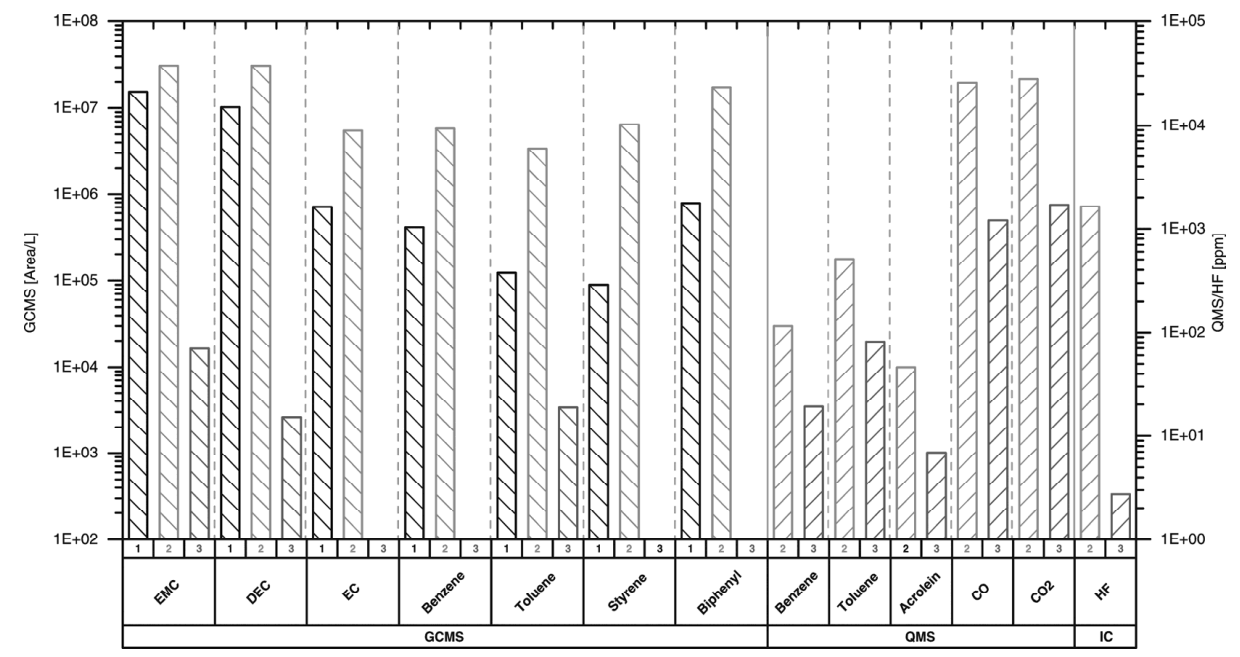

Figure 4. Results of the GC-MS, QMS investigations and HF detection for 11 determinant gas constituents for all three scenarios (1-3). 
Table 1. Eleven crucial gas mixture constituents and their hazards. EMC: ethyl methyl carbonate; DEC: diethyl carbonate; EC: ethylene carbonate; CO: carbon monoxide; and COS: carbonyl sulfide.

\begin{tabular}{cl}
\hline Substance & \multicolumn{1}{c}{ Hazards According to EU Regulation (EG) Act 1272/2008 } \\
\hline \multirow{2}{*}{ EMC } & $\begin{array}{l}\text { Eye irritation; flammable liquid; H226; H315; H319; H335; Skin irritation, specific } \\
\text { target organ toxicity-single exposure. }\end{array}$ \\
\hline \multirow{2}{*}{ DEC } & $\begin{array}{l}\text { Eye irritation; flammable liquid; H226; H315; H319; H335; skin irritation; specific } \\
\text { target organ toxicity-single exposure. }\end{array}$ \\
\hline \multirow{2}{*}{ EC } & $\begin{array}{l}\text { Eye irritation; H315; H319; H335; skin irritation; specific target organ } \\
\text { toxicity-single exposure. }\end{array}$ \\
\hline \multirow{2}{*}{ Benzene } & $\begin{array}{l}\text { Aspiration hazard; carcinogenicity; eye irritation; H225; H304; H315; H319; H340; } \\
\text { H350; H372; germ cell mutagenicity. }\end{array}$ \\
\hline \multirow{2}{*}{ Styrene } & $\begin{array}{l}\text { Aspiration hazard; flammable liquid; H225; H304; H315; H336; H361d; H373; } \\
\text { reproductive toxicity; skin irritation; specific target organ toxicity-repeated exposure. }\end{array}$ \\
\hline \multirow{2}{*}{ Biphenyl } & $\begin{array}{l}\text { Acute toxicity; eye irritation; flammable liquid.; H226; H315; H319; H332; H361d; } \\
\text { H372; Skin irritation; Specific target organ toxicity-repeated exposure. }\end{array}$ \\
\hline Aquatic acute toxicity; aquatic chronic toxicity; eye irritation; H315; H319; H335; \\
H400; H410.
\end{tabular}

As QMS and HF detection were not performed for Scenario 1, these data are missing within the graph. The entire list of components and individual concentrations for each scenario can be found in the Supplementary Materials, namely "GCMS Measurement, Activated Charcoal, Scenario 1.pdf", "GCMS Measurement, Activated Charcoal, Scenario 2.pdf" and "GCMS Measurement, Activated Charcoal, Scenario 3.pdf".

Even without further description, it can be clearly seen that the gas emission from Scenario 2 provokes the highest concentration for each of the selected species. Furthermore, the after filtration measurements show even lower concentrations compared to Scenario 1. For this scenario the lowest concentrations of organic components were expected due to their reaction with environmental oxygen $\left(\mathrm{O}_{2}\right)$ to $\mathrm{CO}_{2}$ and $\mathrm{H}_{2} \mathrm{O}$. The reason for this behavior can be explained as follows: Scenario 1 was chosen to represent the event of a battery failure without any further security measures. In this case the cell expands until it bursts open and catches fire. As the outgassing of the cell within the barrel occurs abruptly (see the video "Experimental Setup Scenario 2.mp4" and freeze frame "Experimental Setup Scenario 2 Still.jpg" in online version in Supplementary Materials), it is assumed that the available quantity of $\mathrm{O}_{2}$ is insufficient for an accomplished oxidation of all components, because the gas from the cell displaces the environmental air in the barrel. Therefore, only part of the volatile organic compounds feed the combustion, whereas a considerable amount still emerges as fume. This fume mainly consists of the electrolyte's main constituents EMC and EC, with traces of the pollutants diethyl carbonate (DEC), benzene, toluene, styrene, and biphenyl.

As the case of a burning cell must be strictly avoided because of the cascaded inflammation of neighboring cells, which is most likely to occur, the first security measure is to suppress the inflammation of the emission gases, thus drastically reducing the amount of energy released. This was achieved by using a textile composite material enclosing the cell and thereby prohibiting flying sparks 
while being permeable for the emission gases [16]. For this case (Scenario 2), almost no oxidation takes place. Consequently, a larger amount and a respective higher quantity of unburned organic substances were expected and could be verified by the analytical methods. All in all, 155 different constituents were found and particularly the concentration of the aforementioned components increased significantly (Figure 4). In addition to the mentioned constituents, a large number of several other organic substances can be seen, most of them are highly flammable and irritating and, thus, dangerous and unpredictable (Figure $3 a, b$ ). The results of the GC-MS from the silica gel tube do not show any subsidiary information, but nevertheless verify the results of the GC-MS from the activated charcoal tube. The reason for the large amount of different organic components that were found is mainly the lack of $\mathrm{O}_{2}$ in combination with high temperatures. Under these conditions, pyrolysis leads to homolytic cleavage of the $\mathrm{C}-\mathrm{O}$ single bonds to form free ethyl and methyl radicals, mainly from the electrolyte's main component EMC. Random combinations of these free radicals can end up in a recombination to EMC, as well as the combination to dimethyl carbonate (DMC) (although not detected here) and DEC (Figure 5).<smiles>CCOC(=O)O[18O]C(=O)OCC</smiles><smiles>CCOC(=O)OCC</smiles>

Figure 5. Homolytic cleavage and radical combination can form DEC and DMC from EMC.

Nevertheless the authors noticed DMC in further experiments with the same type of cell that are not part of this paper. For the GC-MS spectra shown in Figure 3, the detection of molecules started at a retention time of around $5 \mathrm{~min}$ to fade out the solvents. This retention time is too long for the detection of DMC that has its peak at around 4.85 min.

Alongside with free methyl and ethyl radicals, the formation of free vinyl and ethylene radicals is highly probable. The free vinyl radicals are able to combine to 1,3-butadiene. After radicalization butadiene, itself, can add an ethylene radical to form benzene. In a termolecular or stepwise reaction, benzene can also be formed from three free ethylene radicals. Additional reactions of benzene with free methyl and/or vinyl radicals lead to toluene, xylene, and styrene. Homolytic cleavage of a $\mathrm{C}-\mathrm{H}$ bond in benzene forms the free phenyl radical $\mathrm{C}_{6} \mathrm{H}_{5}$ that can dimerize, forming biphenyl. Polycyclic aromatic compounds (PAH), like naphthalene, can be formed in similar reactions [17]. In Figure 6, a short overview of those reactions is shown.

Smaller molecules were detected via QMS. The corresponding spectrum (Figure 3c) shows that the major components of ambient air, such as nitrogen $\left(\mathrm{N}_{2}\right), \mathrm{O}_{2}$, water $\left(\mathrm{H}_{2} \mathrm{O}\right)$, carbon monoxide $(\mathrm{CO})$ and dioxide $\left(\mathrm{CO}_{2}\right)$, as well as argon (Ar), are still present, though at different fractions. Due to the experimental realization, several days of storage time occurred for the transfer from the gas emission experiment to the QMS. After this duration, the gas components with large molecular masses were expected already to be settled on the walls of the gas bag. Indeed, the EMC, DEC, EC, and biphenyl fractions found within the GC-MS spectra cannot be seen by QMS, even if they should be observable with both techniques. Toluene and benzene were found according to their major peaks at $91 \mathrm{u}(115 \mathrm{ppm})$ and $78 \mathrm{u}(505 \mathrm{ppm})$, respectively, while fragments of styrene can be ruled out due to the missing 
peak at $89 \mathrm{u}$. In addition to the toluene and benzene, clear signs of carbonyl sulfide (COS), chlorine dioxide $\left(\mathrm{ClO}_{2}\right)$, sulfur dioxide $\left(\mathrm{SO}_{2}\right)$, and trifluormethane (fluoroform) can be recognized according to their major fragments at $60 \mathrm{u}, 66 \mathrm{u} / 67 \mathrm{u}, 64 \mathrm{u}$, and $69 \mathrm{u}$, respectively. With its peak at $55 \mathrm{u} / 56 \mathrm{u}$, acrolein $(46 \mathrm{ppm})$ is particularly critical because of its highly toxic properties (Table 1$)$. The simplest unsaturated aldehyde acrolein is a common byproduct of oxidation processes. Its objectionable odor is e.g., created on the extinction of candles. It also occurs in tobacco smoke or in smoke from wild fires.

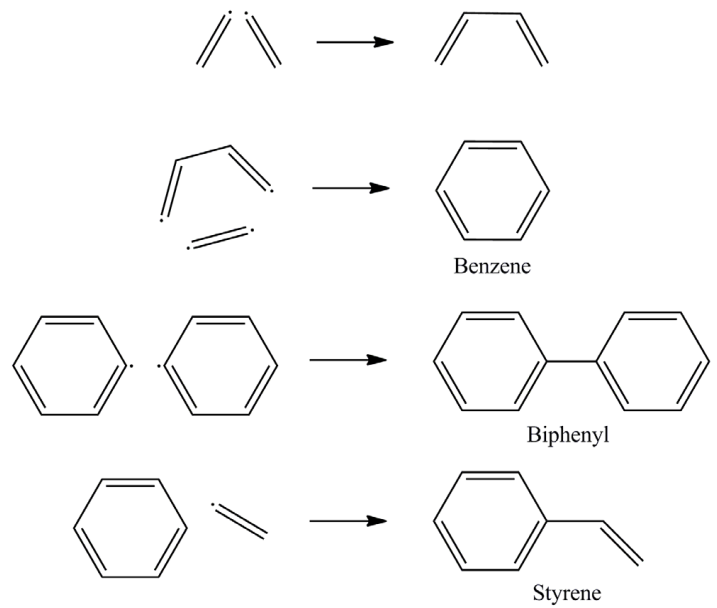

Figure 6. Four exemplary radical reactions that form benzene, biphenyl, and styrene. More reactions underlying similar principles lead to the large amount of different aromatic constituents that were found [17].

The detected fragments of substances with equal atomic mass, like $\mathrm{N}_{2}$ and $\mathrm{CO}$, are occasionally difficult to allocate with QMS. To verify these assigned values with QEPAS, an additional measurement method is available to retrieve additional information about the target gas mixture by addressing its absorption spectrum and its temporal behavior. The QEPAS measurement of $\mathrm{CO}$ gives a good idea of the temporal behavior of the processes involved. The measured concentration matches with the QMS data, considering the error assigned to the overlapping with $\mathrm{N}_{2}$. For the measurement of reactive components, like substances with high electronegativity or large molecules that adsorb until their detection, QEPAS can be an additional analytical method. Especially, the use of a widely tunable laser in the mid infrared spectral region would provide an additional dataset for the whole gas mixture, thus increasing the accuracy of measurement [18].

Another hazardous substance of central importance is HF, which results mainly from the decomposition of the conducting salt $\mathrm{LiPF}_{6}$; in Scenario $21640 \mathrm{ppm}$ were found, which is more than 50 times higher than the immediately dangerous to life or health (IDLH) value. This concentration would lead to fatal consequences for a human being within a few minutes, since the reported emergency exposure limit (EEL) for $10 \mathrm{~min}$ is only $20 \mathrm{ppm}$ [19].

As clarified by the evaluation and comparison of the experiments of Scenario 1 and 2, a suppression of the flame formation in the case of a thermal runaway is much more critical concerning the danger of the emerging gas. However, the ignition of the gas mixture in battery storages cannot be justified since it comes along with unpredictable risks. Therefore, in Scenario 3 an additional neutralization filter system for the emission gasses was tested to diminish the hazardous potential.

After passing the filter element, as described above, only three substances were found via GC-MS with significantly lower values, namely EMC, DEC, and toluene (Figure 4). Consistent with these results, the QMS also demonstrates that the concentrations of the hazardous gas components are strongly reduced by the filter system. In particular, the benzene, toluene, acrolein, and $\mathrm{SO}_{2}$ contents were reduced to less than $20 \%$ of their initial fraction. The $\mathrm{COS}, \mathrm{ClO}_{2}$, and fluoroform emissions, however, dropped below the measurement range of the used spectrometer. For HF, a high filtration 
efficiency could be achieved, too. In Scenario 3, the measured concentration was merely $3 \mathrm{ppm}$ and, thus, significantly below the IDLH value of $30 \mathrm{ppm}$ and more than 500 times lower than in Scenario 2 . The majority of the organic compounds are removed by adsorption on activated charcoal. The efficiency of adsorption increases with molecule size and similarity to the graphite structure (aromatics). The major portion of acid gases, such as HF, is presumably filtered out by chemisorption of the alkaline part of the filter system, the activated alumina. Following Equation (1), the fluorine is trapped as aluminum fluoride under formation of $\mathrm{H}_{2} \mathrm{O}$ [20]:

$$
\mathrm{HF}+\mathrm{OH}^{-} \rightarrow \mathrm{F}^{-}+\mathrm{H}_{2} \mathrm{O}
$$

The measurements from Scenario 3 show highly-promising filtration rates for all hazardous components under test. It should be mentioned that a leak in the barrel-filter unit construction leads to a loss of some of the venting gas from the battery; the loss is estimated to be lower than $15 \%$. However, the measured data should not be affected by this as the increased pressure in the barrel inhibited the influx of ambient air and, therefore, a decrease in the measured concentrations is unlikely. Furthermore, the gas was sucked from a gas collecting bag with a volume of nearly zero at the beginning; thus, only filtered gas was sucked to the measuring devices.

Even though the slight overcharging to $4.3 \mathrm{~V}$ could affect the gas within the cell due to a beginning decomposition, this effect can be neglected because a commercial cell at this voltage usually is far from a critical point. In addition, this paper is mainly focused on the reduction of risk potential by additional safety measures and less on the exact gas composition for different cell states.

\section{Conclusions}

By the outgassing of a lithium ion battery due to a thermal runaway, a dangerous gas mixture with highly explosive, hazardous, and carcinogenic components is released. If no counteractive measures are taken, the cell's failure leads most likely to an ignition, which must be excluded, as there is a great risk of a cascaded runaway of adjacent cells. However, with an inflammation of the battery gas, some of the hazardous substances get oxidized into harmless reaction products, as shown by the performed measurements. If the ignition of the cell is prevented, which can be done most effectively by a textile composite, the gas emission is far more dangerous. Consequently, a gas filtration system has been developed by which adsorption or neutralization processes reduce the concentration of the hazardous components. In a first trial, a selection of filtering materials and a subsequent analysis of the gases released by the filter unit showed very promising results, reducing the concentration of all relevant components well below the amount of the inflammation measurement. The success of these experiments conducted once, will be used in further investigations in order to realize a reliable and cost efficient filter unit which reaches IDLH, or comparable values, for all relevant emitted species.

The combination of the flame-inhibiting textile and the gas filter unit may be used in stationary systems for home storage, or even large scale storage applications, enhancing the security level of the state-of-the-art battery storage to the next level without changing the fundamental cell design.

Supplementary Materials: The following are available online at www.mdpi.com/2313-0105/2/1/5/s1, Experimental Setup Scenario 2.mp4, Experimental Setup Scenario 2 Still.jpg, GCMS Measurement, Activated Charcoal, Scenario 1.pdf, GCMS Measurement, Activated Charcoal, Scenario 2.pdf, GCMS Measurement, Activated Charcoal, Scenario 3.pdf.

Acknowledgments: Financial support from the investment and development bank of Lower Saxony (Project No. ZW3-80140889) is gratefully acknowledged.

Author Contributions: Antonio Nedjalkov and Jan Meyer were responsible for the project, the conducted experiments and the writing of the paper. Alexander Doering initialized the experiments and developed the principle filter design. Michael Köhring was responsible for the QEPAS measurements and helped writing the paper. Sebastian Dahle was responsible for the QMS measurements and assisted to analyze the data. Andreas Sander developed the FlotreX composite material and supported the performed experiments. Axel Fischer was responsible for the chemical analysis of HF, the GCMS measurements and helped writing the paper. Martin Angelmahr was the project manager and Wolfgang Schade supported the project as the head of the institute.

Conflicts of Interest: The authors declare no conflict of interest. 


\section{References}

1. Leadbetter, J.; Swan, L.G. Selection of battery technology to support grid-integrated renewable electricity. J. Power Sources 2012, 216, 376-386. [CrossRef]

2. Beaudin, M.; Zareipour, H.; Schellenberglabe, A.; Rosehart, W. Energy storage for mitigating the variability of renewable electricity sources: An updated review. Energy Sustain. Dev. 2010, 14, 302-314. [CrossRef]

3. Rand, D.A.J.; Moseley, P.T. Energy Storage with Lead-Acid Batteries. In Electrochemical Energy Storage for Renewable Sources and Grid Balancing; Moseley, P.T., Garche, J., Eds.; Elsevier: Amsterdam, The Netherlands, 2015; Chapter 13; pp. 201-222.

4. Kurzweil, P. Lithium Battery Energy Storage: State of the Art Including Lithium-Air and Lithium-Sulfur Systems. In Electrochemical Energy Storage for Renewable Sources and Grid Balancing; Moseley, P.T., Garche, J., Eds.; Elsevier: Amsterdam, The Netherlands, 2015; Chapter 16; pp. 269-307.

5. Ren, G.; Ma, G.; Cong, N. Review of electrical energy storage system for vehicular applications. Renew. Sustain. Energy Rev. 2015, 41, 225-236. [CrossRef]

6. Wang, Y.; Liu, B.; Li, Q.; Cartmell, S.; Ferrara, S.; Deng, Z.D.; Xiao, J. Lithium and lithium ion batteries for applications in microelectronic devices: A review. J. Power Sources 2015, 286, 330-345. [CrossRef]

7. Lisbona, D.; Snee, T. A review of hazards associated with primary lithium and lithium-ion batteries. Process Saf. Environ. Prot. 2011, 89, 434-442. [CrossRef]

8. Wang, Q.; Ping, P.; Zhao, X.; Chu, G.; Sun, J.; Chen, C. Thermal runaway caused fire and explosion of lithium ion battery. J. Power Sources 2012, 208, 210-224. [CrossRef]

9. Doughty, D.H.; Crafts, C.C. FreedomCAR Electrical Energy Storage System Abuse Test Manual for Electric and Hybrid Electric Vehicle Applications; Sandia Report SAND2005-3123. Sandia National Laboratories: Albuquerque, NM; Livermore, CA, USA, 2006.

10. Abraham, D.P.; Roth, E.P.; Kostecki, R.; McCarthy, K.; MacLaren, S.; Doughty, D.H. Diagnostic examination of thermally abused high-power lithium-ion cells. J. Power Sources 2006, 161, 648-657. [CrossRef]

11. Larsson, F.; Andersson, P.; Blomqvist, P.; Lorén, A.; Mellander, B.-E. Characteristics of lithium-ion batteries during fire tests. J. Power Sources 2014, 271, 414-420. [CrossRef]

12. Ohsaki, T.; Kishi, T.; Kuboki, T.; Takami, N.; Shimura, N.; Sato, Y.; Sekino, M.; Satoh, A. Overcharge reaction of lithium-ion batteries. J. Power Sources 2005, 146, 97-100. [CrossRef]

13. Stein, S.E. “Mass Spectra” in NIST Chemistry WebBook: NIST Standard Reference Database Number 69. Available online: http:/ / webbook.nist.gov/ (accessed on 29 September 2015).

14. Kosterev, A.A.; Bakhirkin, Y.A.; Curl, R.F.; Tittel, F.K. Quartz-enhanced photoacoustic spectroscopy. Opt. Lett. 2002, 27, 1902-1904. [CrossRef] [PubMed]

15. Sigma-Aldrich. SDS Search and Product Safety Center. Available online: http://www.sigmaaldrich.com/ safety-center.html (accessed on 31 August 2015).

16. K.TeX-Knein Technische Textilien GmbH. Insulation Materials for Lithium Ion Batteries. Available online: http:/ / www.ktex-gmbh.de/images/Anwendungen/Product-Portfolio-Insulation-Materials-for-LithiumIon-Batteries.pdf (accessed on 29 September 2015).

17. Ballschmiter, K.; Bacher, R. Dioxine: Chemie, Analytik, Vorkommen, Umweltverhalten und Toxikologie der Halogenierten Dibenzo-p-Dioxine und Dibenzofurane; VCH: Weinheim, Germany; New York, NY, USA; Basel, Switzerland; Cambridge, UK; Tokyo, Japan, 1996. (In German)

18. Curl, R.F.; Capasso, F.; Gmachl, C.; Kosterev, A.A.; McManus, B.; Lewicki, R.; Pusharsky, M.; Wysocki, G.; Tittel, F.K. Quantum cascade lasers in chemical physics. Chem. Phys. Lett. 2010, 487, 1-18. [CrossRef]

19. Centers for Disease Control and Prevention. Hydrogen Fluoride (as F). Available online: http://www.cdc.gov/ niosh/idlh/7664393.html (accessed on 26 February 2016).

20. Ingenieurbüro Oetzel. Aufnahmevermögen von Aktivkohle Gegenüber Chemischen Einzelverbindungen. Available online: http:/ / www.umweltanalytik.com/daten/aktivkohle.htm (accessed on 26 February 2016). (In German)

(C) 2016 by the authors; licensee MDPI, Basel, Switzerland. This article is an open access article distributed under the terms and conditions of the Creative Commons by Attribution (CC-BY) license (http:/ / creativecommons.org/licenses/by/4.0/). 